\title{
Analysis of the Use of Fatty Acid Methyl Esters as an Additive to Diesel Fuel for Internal Combustion Engines
}

\author{
${\text { Łukasz Muślewski }{ }^{1} \text {, Marietta Markiewicz }}^{1, * \mathbb{D}}$, Michał Pająk ${ }^{2} \mathbb{D}$, Tomasz Kałaczyński ${ }^{1}$ and Davor Kolar $^{3} \mathbb{D}$ \\ 1 Faculty of Mechanical Engineering, Bydgoszcz University of Science and Technology, Al. Prof. S. Kaliskiego 7, \\ 85-796 Bydgoszcz, Poland; lukasz.muslewski@pbs.edu.pl (Ł.M.); tomasz.kalaczynski@pbs.edu.pl (T.K.) \\ 2 Faculty of Mechanical Engineering, University of Technology and Humanities in Radom, Stasieckiego 54, \\ 26-600 Radom, Poland; m.pajak@uthrad.pl \\ 3 Faculty of Mechanical Engineering and Naval Architecture, University of Zagreb, Ivana Lučića Street 5, \\ 10002 Zagreb, Croatia; davor.kolar@fsb.hr \\ * Correspondence: marmar000@pbs.edu.pl
}

Citation: Muślewski, Ł.; Markiewicz, M.; Pająk, M.; Kałaczyński, T.; Kolar, D. Analysis of the Use of Fatty Acid Methyl Esters as an Additive to Diesel Fuel for Internal Combustion Engines. Energies 2021, 14, 7057 https://doi.org/10.3390/en14217057

Academic Editor: Dimitrios

C. Rakopoulos

Received: 30 September 2021

Accepted: 23 October 2021

Published: 28 October 2021

Publisher's Note: MDPI stays neutral with regard to jurisdictional claims in published maps and institutional affiliations.

Copyright: (c) 2021 by the authors. Licensee MDPI, Basel, Switzerland. This article is an open access article distributed under the terms and conditions of the Creative Commons Attribution (CC BY) license (https:/ / creativecommons.org/licenses/by/ $4.0 /)$.

\begin{abstract}
This study presents pro-ecological activities focused on an analysis of the use of biofuels as an environmentally friendly fuel. The research objects were different concentration mixtures of diesel fuel and fatty acid methyl esters, that is, transesterified plant oils. The tests involved an assessment of the performance parameters of a drive unit in a vehicle powered by diesel fuel for different mixtures of diesel oil and fatty acid methyl esters in the following proportions: $10 \%, 30 \%$, $50 \%$ and $50 \%$ with chemical additives. The tests were comparative and were conducted for 'pure' diesel $(\mathrm{ON})$. The study presents test results of selected performance parameters of the analyzed power unit. The object of the tests was a self-injection engine with a maximum power of $81 \mathrm{~kW}$. The main tests which were most important for assessment of the mixtures, from the point of view of their effect on the analyzed performance parameters, involved measuring power and torque, and the toxic components of exhaust gases. Based on the obtained results, a statistical analysis was carried out, and a model for the evaluation of how the research object functions when fed with different fuel mixtures was developed. The research found which mixture can be considered the most optimal, and what the influence of individual fuel mixtures is on the analyzed performance parameters of the tested power unit.
\end{abstract}

Keywords: transport; engines; diesel oil; biocomponents; environment; sustainable development

\section{Introduction}

Due to rapid technological and economic development, many countries have introduced economic changes to improve efficiency of production and management, focusing on the ecological character of legislation and the relevant actions to be taken. The use of renewable energy sources to produce transport fuel for combustion engines is dictated by a high demand for fuel and the depletion of natural resources. The structures of combustion engines enable their modernization and, subsequently, a return to the idea of plant fuels. The exhaustion of petroleum fuels is an argument for turning to the concept of plant fuels. Plant oils are considered to be the best for this purpose. The most common biofuels include rape oil, soya oil, sunflower oil, arachis oil and animal fats. The above-listed plant fuels, referred to as biofuels, must undergo chemical processing to achieve physical-chemical properties similar to those of diesel oil. Rape oil is most frequently used for economic, technical, structural and technological reasons. The results of research provided by many scientific centers prove that the physical-chemical properties of rape biofuel are the most similar to diesel, which makes it the number one biofuel when compared to other biofuels. The content of oil and hydrogen in rape oil is lower than in traditional diesel, whereas its density and viscosity is higher [1]. The application of rape oil involves the presence of sulfur in exhaust emission, and a smaller number of solid particles such as hydrocarbons 
and carbon monoxides. The combustion of conventional fuels in self-ignition engines generates a big amount of sulfur oxide and nitric oxide. Powering self-ignition engines with fatty acid methyl esters causes a reduction in toxic emissions of exhaust gases such as carbon monoxides, hydrocarbons and solid particles [2-7]. Nitric oxides are the exception, as they increase by several percent when compared to pure diesel oil [8]. It needs to be highlighted though, that the most commonly used indicators of combustion engines are: power, torque, fuel consumption, noise emission and the composition of exhaust fumes and exhaust smoke. Tests conducted by other authors have provided $7 \%$ lower values in engine performance parameters and a lower power reduction compared to diesel, depending on the combustion system and characteristics of the injection unit $[8,9]$. According to the literature, using renewable energy sources to power combustion engines reduces the emission of pollution of such exhaust components as: carbon monoxide, hydrocarbons and particulates [5,7-17]. Nitric oxides, which cause an increase of several percent compared to diesel, are the exceptions. The use of biofuels combined with low temperature combustion can be a way to improve the economy of fuel management and emission reduction. However, research centers and the industry are working on innovative combustion systems to reduce $\mathrm{CO} 2$ emission and improve NOx-Soot trade-offs, such as additive manufacturing, bowl design, innovative fuel injection systems, injection strategy and EGR systems [18,19].

The goal of this study is to analyze the advisability of the application of one type of alternative fuel, mixtures of diesel and fatty acid methyl esters, as well as evaluate their impact on the selected performance parameters that characterize the operation of the research object-the power unit of a transport means. The main subject of this work is to find out which mixtures of fatty acid methyl esters with diesel oil would have the performance parameters of diesel, as well as assess their environmental impact. A multicriteria and comprehensive analysis of the impact of the use of biofuels on the change of the basic performance parameters of drive units is a new approach to the subject.

\section{The Research Materials}

The research objects were mixtures with different concentrations of diesel fuel and fatty acid methyl esters, that is, plant oils subjected to transesterification-a process of exchanging glycerin bonded in a triacyloglicerole molecule with methyl alcohol catalyzed by the addition of base or acid catalyst—commonly known as a biocomponent.

In the main tests, the performance parameters of a transport-means drive unit, powered by mixtures of diesel fuel with fatty acid methyl esters, were measured according the following proportions:

- $\quad 10 \%$ of fatty acid methyl esters and $90 \%$ of diesel oil,

- $\quad 30 \%$ of fatty acid methyl esters and $70 \%$ of diesel oil,

- $\quad 50 \%$ of fatty acid methyl esters and $50 \%$ of diesel oil,

- $\quad 50 \%$ fatty acid methyl esters with chemical additives and $90 \%$ diesel oil.

A chemical additive introduced to the mixture of $50 \%$ diesel fuel with $50 \%$ fatty acid methyl esters was a substance which increased the lubrication properties of the fuel and its cetane number. Table 1 presents a comparison of the results for diesel oil, biodiesel and plant oil.

Table 1. Physical chemical properties of fuels used in combustion engines.

\begin{tabular}{cccc}
\hline Property & Diesel Oil & Biodiesel & Plant Oil \\
\hline Viscosity $\left[\mathrm{mm}^{2} \mathrm{~s}^{-1}\right]$ & $2.0-4.5$ & $3.5-5.5$ & 7.2 \\
Sulfur content $\left[\mathrm{mg} \cdot \mathrm{kg}^{-1}\right]$ & $\leq 35$ & $\leq 10$ & no \\
Density $\left[\mathrm{g} \cdot \mathrm{cm}^{-3}\right]$ & $0.82-0.45$ & $0.86-0.90$ & 0.88 \\
Cetane number & $\geq 51$ & $\geq 47$ & $>40$ \\
Calorific value $[\mathrm{MJ} / \mathrm{kg}]$ & 43 & 41 & 37.6 \\
Ignition point $\left[{ }^{\circ} \mathrm{C}\right]$ & $\geq 55$ & $\geq 101$ & $\geq 220$ \\
\hline
\end{tabular}


The object of the tests was a self-injection engine with a maximum power of $81 \mathrm{~kW}$. The power unit is considered to be representative as it has a wide application in many vehicles, with a maximum authorized weight up to $3.5 \mathrm{t}$, a $1.6 \mathrm{HDi}$ engine with a Common Rail direct fuel injection system, and the use of electromagnetic injectors. The characteristics of the factory settings of one of the test engines are presented in Figure 1.

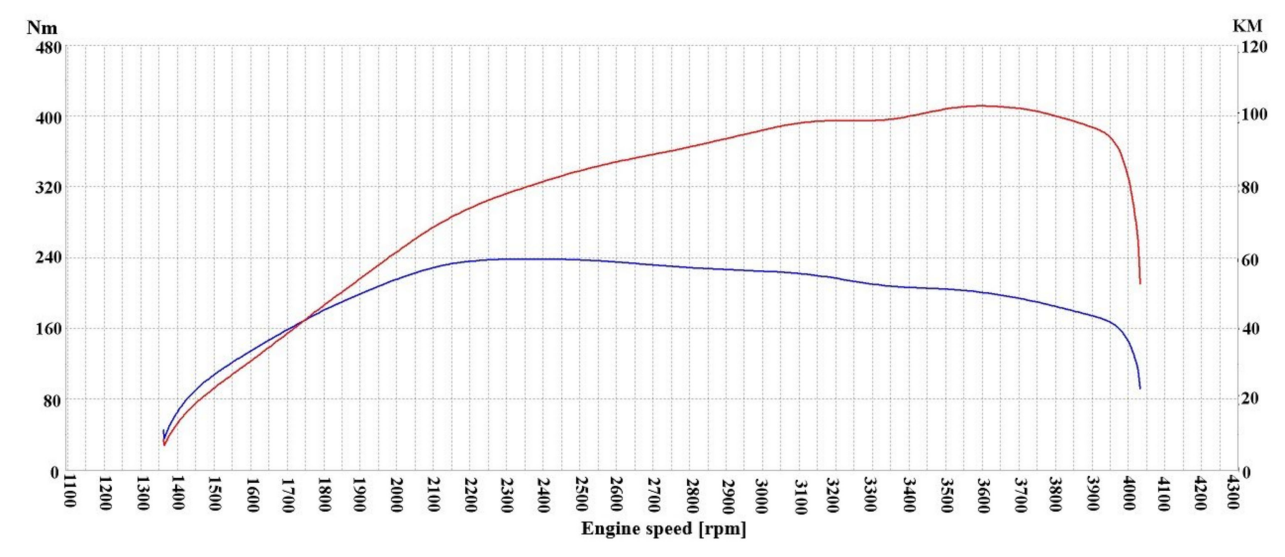

Figure 1. Characteristics of the test engine.

\section{The Research Methods}

The tests were divided into two parts, the initial and main tests, which are presented in Figure 2. The initial tests involved the determination of the value of the energy value and the cetane number of the mixtures of diesel fuel and fatty acid methyl esters. The tests were repeated and carried out in order to determine the content of the mixtures of diesel fuel with a biocomponent. The tests were of comparative character, and were performed for 'pure' diesel (ON). The notion 'pure' diesel fuel refers to a fuel without fatty acid methyl esters. The tests were performed on a chassis dynamometer, simulating road conditions. The following parameters were tested: power, torque, exhaust gas content and content of particulates. The emission of noise generated by the power unit was also assessed.

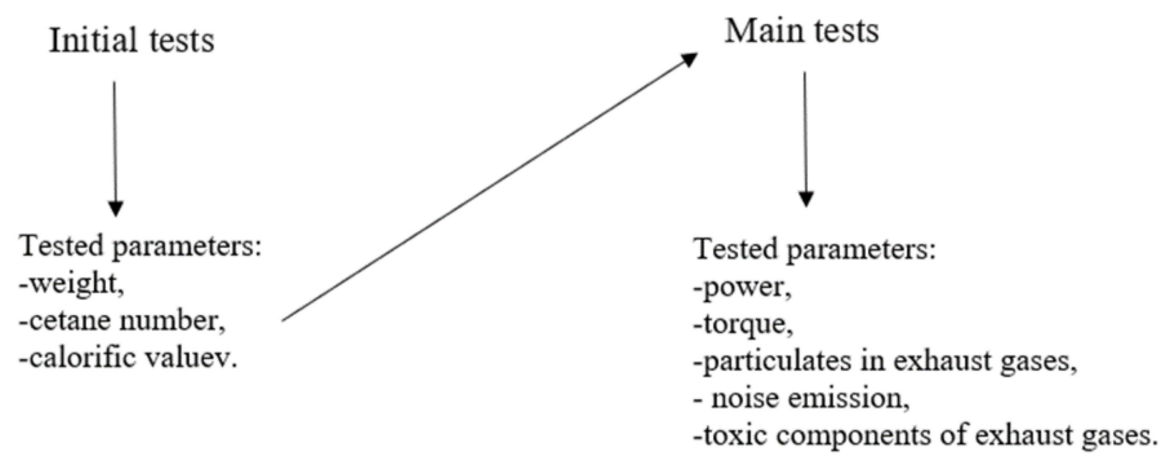

Figure 2. Stages of the tests.

The initial tests, whose aim was to identify the tested material (of particular mixtures), included:

- The measurement of fuel energy parameters—specific heat and calorific value-with the use of a colorimeter;

- A viscosity test-the measurement of the liquid viscosity coefficient-with the use of a rotational viscosimeter;

- the measurement of the cetane number-with the use of a calibrated model engine according to ASTM D613 and PN-EN ISO norms. 
The main tests that played the most important role in the assessment of the mixtures, from the point of view of their effect on the analyzed performance parameters, included measurements of:

- Power and torque-using a load bearing chassis dynamometer with a DynoTech electromechanical brake with a valid manufacturers certificate. Measurements included the impact of air moisture, pressure changes, changes in air temperature and atmospheric pressure, whose values were normalized. The measurement results were calculated onto values corrected in accordance with the applicable standard $\left(25^{\circ} \mathrm{C}\right.$ and $1000 \mathrm{hPa}$ ) norm [20];

- $\quad$ The toxic components of exhaust gases-using an exhaust fume analyzer MGT-5, which along with a periodically validated measuring probe, complied with the requirements provided in $22 / 2004 \mathrm{WE}$ directive. The experimental tests allowed the definition of the values of emitted compounds, which are presented in Table 2;

- The content of solid particles in exhaust gases - the measurement of the emission of solid particles with dimensions exceeding $100 \mathrm{~mm}$ was performed measured with MPM-4 analyzer of Maha company. The analyzer had a certificate of periodic validation;

- The value of noise emission-the test was conducted with the use of a noise level meter with an embedded spectrum analyzer with a validation certificate complying with the requirements of IEC 61672-1:2002 and IEC 60651 norms. The orientation method was used to define the standard power of the engine noise acoustics by calculating the level of power corrected in frequency bands based on the acoustic pressure level in the frequency bands, and the level of noise measured by means of a correction filter.

This section presents a description of the proposed assessment method and an assessment model for the evaluation of the influence of fatty acid methyl ester additives to diesel fuel on the values of selected performance parameters of the analyzed research object.

Table 2. The emitted compounds that were tested.

\begin{tabular}{cc}
\hline Emitted Compounds & Symbol \\
\hline Hydrocarbons & $\mathrm{HC}$ \\
Oxygen & $\mathrm{O}_{2}$ \\
Carbon oxide & $\mathrm{CO}$ \\
Carbon dioxide & $\mathrm{CO}_{2}$ \\
Nitric oxides & $\mathrm{NO}_{2}$ \\
Excess air coefficient & $\lambda$ \\
\hline
\end{tabular}

\subsection{Description of the Assessment Method}

It was established that assessment should be carried out based on tests of the impact of the mixtures of diesel fuel with fatty acid methyl esters on selected measurable performance parameters of the analyzed power unit. The assessment covered parameters that, due to their importance and impact on the test results, were accepted in a mathematical description [21,22]. The assessment process involved the identification of the parameter set $\{X i\} i=1,2, \ldots, p$ (characteristics), describing the tested engines from the point of view of the research purpose. Next, the value of each accepted parameter was measured. At the same time, it must be remembered that the considered set of parameters accepted for assessment consists of two subsets. One of them is a subset whose values are determined based on the measurements, and these are of constant character. The second subset, however, consists of characteristics assessed in a discrete manner. Based on this, the analyzed characteristics are approached in terms of a fuzzy representation [23]. When their values are determined from the measurements, the obtained value is to be defined with accuracy, 
taking into consideration the measurement error [24]. Thus, only the interval containing a given value can be defined, but not the value itself:

$$
\mathrm{X}_{0} \in\left\langle\mathrm{X}_{\mathrm{p}}-\delta_{\mathrm{u}}, \mathrm{X}_{\mathrm{p}}+\delta_{\mathrm{u}}\right\rangle
$$

where:

$\mathrm{X}_{0}$-calculation value of the characteristics;

$\mathrm{X}_{\mathrm{p}}$-measuring value of the characteristics;

$\delta_{\mathrm{u}}$-measuring point of the device.

In the case of direct measurement, the value is additionally burdened with an error of the measurement method. This involves the necessity of accepting a tolerance interval, which needs to be considered when analyzing the results.

In the case of measurements containing insensitivity zones, the tolerance interval was modelled as a fuzzy set of type П:

$$
\mathrm{FS}_{\Pi \Pi}(\mathrm{x})=\left\{\begin{array}{l}
\frac{\mathrm{x}-\mathrm{lrs}}{\mathrm{lrk}-\mathrm{lrs}} \\
\frac{\mathrm{rrs}-\mathrm{x}}{\mathrm{rrs}-\mathrm{rrk}}
\end{array}\right.
$$

where:

$\mathrm{FS}_{\Pi}(\mathrm{x})$ - a function of affinity for a fuzzy set of type $\Pi$;

lrk-the lowest value belonging to the nucleus of fuzzy set;

lrs- the lowest value belonging to the fuzzy set medium;

rrk-the highest value belonging to the fuzzy set nucleus;

rrs-the highest value belonging to the medium of fuzzy set.

In the remaining cases, the tolerance interval was modeled in the form of a fuzzy set of type $\Lambda$ :

$$
\mathrm{FS}_{\Lambda}(\mathrm{x})=\left\{\begin{array}{l}
\frac{\mathrm{x}-\mathrm{lrs}}{\mathrm{lrk}-\mathrm{lrs}} \\
\frac{\mathrm{rrs}-\mathrm{x}}{\mathrm{rrs}-\mathrm{rrk}}
\end{array}\right.
$$

where:

$\mathrm{FS}_{\Lambda}(\mathrm{x})$-function of affinity for the fuzzy set of type $\Lambda$;

lrk - the lowest value belonging to the nucleus of fuzzy set;

lrs-the lowest value belonging to the medium of fuzzy set;

rrs- the highest value belonging to the fuzzy set medium.

The value of a fuzzy set modal was accepted as the measurement value, whereas its medium is equal to the accepted tolerance interval.

In the case of characteristics that make up the second identified set, the assessment can be of subjective character. At the same time, for the assigned discrete scale to be used for grading the respective criterion fulfilment degree, the assessment is determined with approximation, which results from the applied discretization. The above inaccuracy can be modeled by means of fuzzy sets of type $\Lambda$. A modal value is accepted to be the criterion fulfilment degree for the considered set, whereas twice the distance between the discrete values of the rating scale is accepted to be the medium.

3.2. Construction of an Assessment Model for the Impact of a Fatty Acid Methyl Esters Additive to Diesel Fuel on the Values of Performance Parameters of the Considered Means of Transport

Let $X_{i}, i=1,2, \ldots, p$, stand for a feature which is a random variable representing the assessment of a transport means, functioning from the point of view of it being powered by a given fuel mixture. A vector of features:

$$
\mathrm{X}=\left\langle\mathrm{X}_{1}, \mathrm{X}_{2}, \ldots, \mathrm{X}_{\mathrm{p}}>\right.
$$

is considered. 
The component $X_{i}, i=1,2, \ldots, p$, of vector $X$ is a one-dimensional random variable in $R$ space, describing the $i$-th feature, and representing the value of one of the parameters accepted for the evaluation. Vector $X$ is a $p$-dimensional random variable providing a full (collective) assessment of the research object in space $\mathrm{R}^{\mathrm{p}}$. Then, expression:

$$
X \times \Omega \rightarrow R^{p}
$$

means that for each elementary $(\omega)$, where $\omega \in \Omega, X(\omega)$ is a p-dimensional vector, its components are real numbers expressing the analyzed parameters of the mixture fueling in the transport-means power unit, where:

$\mathrm{X}-\mathrm{p}$-dimensional assessment vector;

$\Omega$-set of elementary events;

$\omega$-elementary event;

$\mathrm{R}^{\mathrm{p}}-\mathrm{p}$-dimensional space made up of vectors $(\mathrm{x} 1, \mathrm{x} 2, \ldots, \mathrm{xp})$;

$x_{i}-p$-element sequences; $x_{i} R, i=1,2, \ldots$, $p$.

For a given research object, the random variable is defined in the form:

$$
\mathrm{Z}_{\mathrm{x}}=\sum_{\mathrm{i}=1}^{\mathrm{p}} \alpha_{\mathrm{i}} \mathrm{X}_{\mathrm{i}}
$$

where:

$$
\alpha_{\mathrm{i}} \geq 0, \quad \sum_{\mathrm{i}=1}^{\mathrm{p}} \alpha_{\mathrm{i}}=1,
$$

$\alpha_{i}, i=1,2, \ldots, p$-denote the values of weights for each parameter;

$Z_{X}-$ a random variable being a finite mixture of variables $X_{i}, i=1,2, \ldots, p$.

For the mean value, it can be:

$$
\mathrm{EZ}_{\mathrm{x}}=\sum_{\mathrm{i}=1}^{\mathrm{p}} \alpha_{\mathrm{i}} \mathrm{EX}_{\mathrm{i}}
$$

Mean value EZX is a linear combination of mean values $\mathrm{EX}_{i}, \mathrm{i}=1,2, \ldots$, $\mathrm{n}$. The formula finds application even if variables $X_{i}, i=1,2, \ldots, n$ are dependent ones.

With these considerations, the aim of the study is to compare the fueling of the propulsion unit with different mixtures in relation to the standardized mixture, or adopted as a reference point ('pure' diesel), and, based on this, determine the impact of each mixture on the respective performance parameters. It should to be noted that the values of the parameters describing the test samples may be less, equal or higher than the values of the parameters that are the point of reference. Thus, in a graphic interpretation (Figure 3), the length of the components of vector $\mathrm{W}^{\mathrm{B}}$ (representing particular values of the parameters describing a given mixture) analogically, can be different or equal to the components of vector $\left(\mathrm{W}^{\mathrm{B}}\right)$ (representing values of parameters for 'pure' diesel), and a comprehensive assessment will result from the total values of the particular parameters and assign to them weights.

A multi-criteria optimization analysis was used in the assessment process, in consideration of the above case. This involves arranging the assessed variants in a specific order and, if possible, determining the overall quality of each variant by assigning to them appropriate degrees and results. The application of this analysis allows:

- The determination of the criteria that make up the multi-criteria optimization assessment system - quantitative and qualitative criteria; the common method to be used for assigning a grade to each variant, according to each criterion being an object of the same domain;

- $\quad$ The determination of a system of weights for each criterion;

- The determination of a system of weights for a particular decision makers' assessments;

- The implementation of the calculation process for an overall assessment of a given variant; 
- The interpretation of the overall assessment provided.

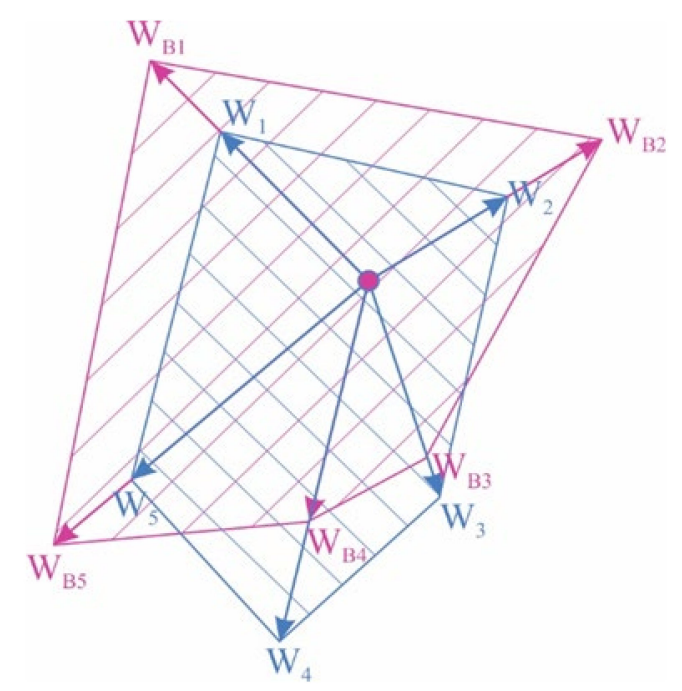

Figure 3. Test stages.

The MOA SMART and AHP methods are proposed for the multi-criteria optimization analysis $[25,26]$. In the process of assessment, the AHP (Analytic Hierarchy Process) is used for the determination of the weights of particular criteria [27-29]. It enables the specification of the expert's knowledge in a way that is natural for a human mind. A scale is provided to assign numerical values to verbal comparisons. It is a method of comparing parameters that can be represented in the form of a matrix:

$$
\mathrm{q}=\left[\begin{array}{cccc}
0 & \mathrm{q}_{1,2} & \ldots & \mathrm{q}_{1, \mathrm{n}} \\
0 & 0 & \ldots & \vdots \\
0 & 0 & 0 & \mathrm{q}_{\mathrm{n}-1, \mathrm{n}} \\
0 & 0 & 0 & 0
\end{array}\right]
$$

The determination of the values of grades defining the significance of the analyzed parameters is carried out based on a seven-degree grading scale, described in Table 3 . The grading scale was selected according to the AHP method.

Table 3. Grading scale used in a comparative assessment of the parameters.

\begin{tabular}{ccc}
\hline Comparison of Variant $a$ with Variant $\boldsymbol{b}$ & Relative Quality of Variant $\boldsymbol{a}$ as Compared to $\boldsymbol{b}$ & Assigned Value $\boldsymbol{q}_{\boldsymbol{a} \boldsymbol{b}}$ \\
\hline$a$ much better than $b$ & Strong preference of $a$ & 6 \\
\hline$a$ better than $b$ & Preference of $a$ & 4 \\
\hline$a$ a little better than $b$ & Peak preference of $a$ & 2 \\
\hline$a$ equally good as $b$ & No preference & 0 \\
\hline$a$ slightly worse than $b$ & Weak preference of $b$ & -2 \\
\hline$a$ worse than $b$ & Preference of $b$ & -4 \\
\hline$a$ much worse than $b$ & Strong preference of $b$ & -6 \\
\hline
\end{tabular}

According to the presented method, the values of the weights are determined based on the dependence:

$$
\mathrm{w}_{\mathrm{wj}}=\frac{1}{\mathrm{n}_{\mathrm{w}}} \sum_{\mathrm{k}=1}^{\mathrm{n}_{\mathrm{w}}} \mathrm{q}_{\mathrm{wjk}}
$$


where:

$\mathrm{q}_{\mathrm{wjk}}$-value of the preference criterion with index $\mathrm{w}_{\mathrm{j}}$, in relation to a criterion with index $\mathrm{k}$; $\mathrm{n}_{\mathrm{w}}$-number of criteria;

$\mathrm{w}_{\mathrm{wj}}$-value of weight for the $\mathrm{w}_{\mathrm{j}}$-th criterion.

\section{Results}

\subsection{Initial Tests}

The tests (anti-anti-anti-anti) involved the use of different test methods. The samples were observed in order to define the negative phenomena of delamination, gelation and others. The samples were put into containers for protection against light and air for approximately $72 \mathrm{~h}$, at a constant temperature of $210^{\circ} \mathrm{C}$. The solutions were examined after $12 \mathrm{~h}$. The properties affecting the engine operation were identified in the next stage of the tests. Calorific value and the mass of ash left after burning the fuel, cetane number and viscosity were tested. An assessment of calorific value of the samples was performed by means of a KL-12Mn calorimeter by burning $1 \mathrm{~g}$ of fuel in the atmosphere of oxygen, in a glass pot. After each test, the mass of ash from burning was defined. Tests were repeated three times for each fuel. A measurement of the viscosity coefficient was performed with the use of a rotating viscometer, at a temperature of $300{ }^{\circ} \mathrm{C}$, three times. Measurements of the cetane number were made with the engine method. Mean quantities of energetic value, cetane number and viscosity is presented in Table 4.

Table 4. Mean quantities of energetic value, cetane number and viscosity.

\begin{tabular}{cccc}
\hline & $\begin{array}{c}\text { Calorific Value } \\
{\left[\mathbf{M J} \cdot \mathbf{k g}^{-\mathbf{1}}\right]}\end{array}$ & Cetane Number & $\begin{array}{c}\text { Viscosity } \\
{[\mathbf{c S t}]}\end{array}$ \\
\hline Mixture I & 43.096 & 53.50 & 6.47 \\
\hline Mixture II & 43.197 & 53.99 & 6.37 \\
\hline Mixture III & 41.957 & 54.97 & 7.80 \\
\hline Mixture IV & 40.588 & 55.95 & 8.57 \\
\hline Mixture V & 37.903 & 58.40 & 1.87 \\
\hline
\end{tabular}

Based on the observations carried out in the first stage of the tests, it was found that the color of samples III, IV and V had already changed after the first $12 \mathrm{~h}$ (the samples darkened slightly). However, neither the delamination nor coagulation mentioned by other authors [8] were observed. The calorific value of the tested fuels, the ash mass and viscosity did not change statistically significantly for biocomponent content 0 or $10 \%$. For a biocomponent content of $30 \%$ and $50 \%$, a drop in calorific value by approximately $3.4 \%$ was observed, compared to samples I and II. However, for sample V, the drop was $12.1 \%$. The course of change for the fuel calorific value and viscosity is demonstrated in Figures 2 and 3. The ash mass is different for fuels with a biocomponent content higher than $30 \%$ (samples III, IV i V) and is lower by about $63 \%$ for fuels with a higher content of biocomponent.

\subsection{Construction of the Assessment Model}

In this study, performance parameters were assessed for their impact on the quality of the analyzed object functioning in the environment. Moreover, the physical-chemical properties of the tested mixtures, such as viscosity, cetane number, calorific value and water content (initial tests), were tested. Fuel consumption tests were neglected, as this subject has already been profoundly analyzed by many authors [7,30-33]. However, the overall costs to be borne in connection with the use of biofuels are the company internal costs and the costs of materials. The costs of materials include diesel fuel and methanol with a catalyst. The catalyst is potassium hydroxide or possibly sodium hydroxide. A ready-touse product (RME biodiesel and technical glycerin) are the profits. This is regardless of the 
fatty acid methyl ester production costs, which depend on the current prices according to the stock exchange listing in Rotterdam [34].

In the proposed model, $X$ denotes one-dimensional vectors, which are accepted as random variables. The analyzed parameters $\left(X_{1} \div X_{10}\right)$ represent the evaluation of transport means powered with mixtures of diesel oil and a variable content of fatty acid methyl esters. Then, the considered vector assumes the following form:

$$
X i=<X_{1}, X_{2}, X_{3}, X_{4}, X_{5}, X_{6}, X_{7}, X_{8}, X_{9}, X_{10}>
$$

where the vector components are:

$\mathrm{X}_{1}$-power;

$x_{2}$-torque;

$\mathrm{X}_{3}$ - emission of sound generated by the engine;

$\mathrm{X}_{4}$-content of particulates in exhaust gases;

$\mathrm{X}_{5}$ - carbon monoxide;

$\mathrm{X}_{6}$ - carbon dioxide;

$\mathrm{X}_{7}$-oxygen;

$\mathrm{X}_{8}$-nitric oxides;

$\mathrm{X}_{9}$-air excess coefficient lambda;

$\mathrm{X}_{10}$-hydrocarbons.

A random variable in the form of:

$$
Z_{x}=\alpha_{1 \times 1}+\alpha_{2 \times 2}+\alpha_{3 \times 3}+\alpha_{4 \times 4}+\alpha_{5 \times 5}+\alpha_{6 \times 6}+\alpha_{7 \times 7}+\alpha_{8 \times 8}+\alpha_{9 \times 9}+\alpha_{10 \times 10}
$$

where $\alpha$ denotes the values of weights (determined by the AHP method) for particular parameters, which are presented in Table 5.

Table 5. Values of weights for particular parameters [35-37].

\begin{tabular}{cccc}
\hline $\begin{array}{c}\text { Vector Component } \\
\text { Denotation }\end{array}$ & $\begin{array}{c}\text { Weight } \\
\text { Denotation }\end{array}$ & Explanation & Weight \\
\hline$X_{1}$ & $\alpha_{1}$ & Power [kW] & 0.2616 \\
\hline$X_{2}$ & $\alpha_{2}$ & Torque [Nm] & 0.45547 \\
\hline$X_{3}$ & $\alpha_{3}$ & Emission of sound generated by the engine [dB] & 0.01239 \\
\hline$X_{4}$ & $\alpha_{4}$ & Content of particulates in exhaust gases [ppm] & 0.2616 \\
\hline$X_{5}$ & $\alpha_{5}$ & Carbon monoxide [\% vol.] & 0.00044 \\
\hline$X_{6}$ & $\alpha_{6}$ & Carbon dioxide [\% vol.] & 0.00235 \\
\hline$X_{7}$ & $\alpha_{7}$ & Oxygen [\% obj.] & 0.00046 \\
\hline$X_{8}$ & $\alpha_{8}$ & Nitric oxides [ppm] & 0.00539 \\
\hline$X_{9}$ & $\alpha_{9}$ & Air excess coefficient lambda & 0.00019 \\
\hline$X_{10}$ & $\alpha_{10}$ & Hydrocarbons [ppm] & 0.00011 \\
\hline
\end{tabular}

\subsection{Results of Experimental Tests}

This study presents a detailed comparative analysis of the values of the performance parameters of a transport-means power unit fueled with mixtures of diesel oil and fatty acid methyl esters.

A comparison of the tested mixtures made it possible to refer to the values obtained for particular performance parameters to a 'pure' diesel, which was used as a reference for the needs of this study. The assessment process is considered to be an example of a multi-criteria optimization analysis (MOA). The assessment is expressed as an arithmetical mean, being the most efficient, unburdened estimator of an unknown expected value [38] 
for particular values of the performance parameters of the transport-means power unit (five mixtures of diesel fuel and fatty acid methyl esters), and is presented in Table 6.

Table 6. Assessment of the values of performance parameters for particular mixtures of diesel fuel and fatty acid methyl esters.

\begin{tabular}{ccccccccccc}
\hline $\begin{array}{c}\text { Mixture } \\
\text { Number }\end{array}$ & $\begin{array}{c}\text { Power } \\
{[\mathbf{k W}]}\end{array}$ & $\begin{array}{c}\text { Torque } \\
{[\mathrm{Nm}]}\end{array}$ & $\begin{array}{c}\text { Noise } \\
{[\mathrm{dB}]}\end{array}$ & $\begin{array}{c}\text { Solid } \\
\text { Particles } \\
{[\mathrm{ppm}]}\end{array}$ & $\begin{array}{c}\text { Carbon } \\
\text { Oxide [\% } \\
\mathbf{o b j . ]}\end{array}$ & $\begin{array}{c}\text { Carbon } \\
\text { Dioxide } \\
{[\% \text { obj.] }}\end{array}$ & $\begin{array}{c}\text { Oxygen } \\
{[\% \text { obj.] }}\end{array}$ & $\begin{array}{c}\text { Nitric } \\
\text { Oxides } \\
{[\mathrm{ppm}]}\end{array}$ & $\begin{array}{c}\text { Lambda } \\
\text { Hydrocarbons } \\
{[\mathrm{ppm}]}\end{array}$ \\
\hline I & 0.8482 & 0.8698 & 0.6826 & 0.5164 & 0.7232 & 0.3464 & 0.5200 & 0.4740 & 0.6048 & 0.6482 \\
\hline II & 0.8888 & 0.8564 & 0.7966 & 0.5008 & 0.7944 & 0.4206 & 0.6706 & 0.4630 & 0.6280 & 0.8122 \\
\hline III & 0.9326 & 0.9282 & 0.6774 & 0.4916 & 0.7230 & 0.4190 & 0.6210 & 0.4794 & 0.6056 & 0.6666 \\
\hline IV & 0.8378 & 0.9494 & 0.6110 & 0.4534 & 0.8058 & 0.4218 & 0.6428 & 0.4746 & 0.5990 & 0.6248 \\
\hline V & 0.9500 & 0.9226 & 0.5982 & 0.4432 & 0.7400 & 0.132 & 0.6236 & 0.3670 & 0.6090 & 0.6350 \\
\hline
\end{tabular}

Tests of a transport-means power unit fueled with different mixtures of diesel and fatty acid methyl esters were conducted every $24 \mathrm{~h}$, with 10 repetitions for each parameter. Based on the tests results, values were determined for each parameter in a given time moment (intervals) ti, $i=1,2,3$. Based on this, the mean values of grades were also determined for particular measurement groups. The values determined for the parameters were recorded so that the minimum values would reflect the worst level, whereas the maximum values would reflect the value desired for particular parameters.

The obtained results allowed the definition of the size of the components of particular vectors. The determination of these components enables the geometric interpretation of the performance parameter mean values for a transport-means power unit fueled with mixtures of diesel and fatty acid methyl esters. For transparency and unambiguity of the results, the values of the relevant parameters from the analyzed set were normalized onto interval $\langle 0 \div 10>$, using the following dependence:

$$
10 \times \frac{\left(X_{i}-X_{\min }\right)}{\left(X_{\max }-X_{\min }\right)}
$$

Furthermore, variability intervals were determined for the set of relevant parameters, which are presented in Table 7.

Table 7. Variability intervals for the set of relevant parameters.

\begin{tabular}{ccc}
\hline Parameter & Minimal Value & Maximal Value \\
\hline Power [kW] & 100.0 & 110.0 \\
\hline Torque [Nm] & 230.0 & 250.0 \\
\hline Noise [dB] & 118.0 & 126.0 \\
\hline Particulates [ppm] & 87.0 & 110.0 \\
\hline Carbon oxide [\% obj.] & 0.05 & 0.2 \\
\hline Carbon dioxide [\% obj.] & 11.0 & 12.8 \\
\hline Oxygen [\% obj.] & 7.0 & 9.0 \\
\hline Nitric oxides [ppm] & 230.0 & 281.0 \\
\hline Lambda & 1.3 & 1.6 \\
\hline Hydrocarbons [ppm] & 10.0 & 60.0 \\
\hline
\end{tabular}

First, the components of the vector which was accepted to be the point of reference, the 'pure' diesel fuel (mixture I), were analyzed. Next, a comparative analysis was performed for the remaining four mixtures. Below are the component values of the parameter 
measurement vector for mixture $\mathrm{V}(50 \%$ diesel fuel and $50 \%$ fatty acid methyl esters with a chemical additive) are presented in Table 8.

Table 8. Average measurement results for mixture V.

\begin{tabular}{|c|c|c|c|c|}
\hline \multirow{2}{*}{ Parameter } & \multicolumn{3}{|c|}{ Measurement Number } & \multirow{2}{*}{ Mean Value } \\
\hline & 1 & 2 & 3 & \\
\hline Power $[\mathrm{kW}]$ & 104.786 & 104.7718 & 104.8774 & 104.8117 \\
\hline Torque $[\mathrm{Nm}]$ & 247.024 & 246.834 & 246.598 & 246.8187 \\
\hline Emission of sound generated by the engine $[\mathrm{dB}]$ & 121.062 & 121.122 & 121.102 & 121.0953 \\
\hline Content of particulates in exhaust gases [ppm] & 88.932 & 88.61 & 89024 & 88.85533 \\
\hline Carbon monoxide [\% vol.] & 0.1584 & 0.0652 & 0.0574 & 0.093667 \\
\hline Carbon dioxide [\% vol.] & 11.9966 & 12.216 & 12.186 & 12.13287 \\
\hline Oxygen [\% obj.] & 9.1444 & 8.2088 & 8.2538 & 8.535667 \\
\hline Nitric oxides [ppm] & 256.32 & 265.28 & 268.56 & 263.3867 \\
\hline Air excess coefficient lambda & 1.53238 & 1.52244 & 1.52428 & 1.526367 \\
\hline Hydrocarbons [ppm] & 27.28 & 24.46 & 27.2 & 27.31333 \\
\hline
\end{tabular}

The results obtained for each parameter were presented in a geometric interpretation (Figure 4) for mixture V, in comparison with the vector, which is the point of reference.

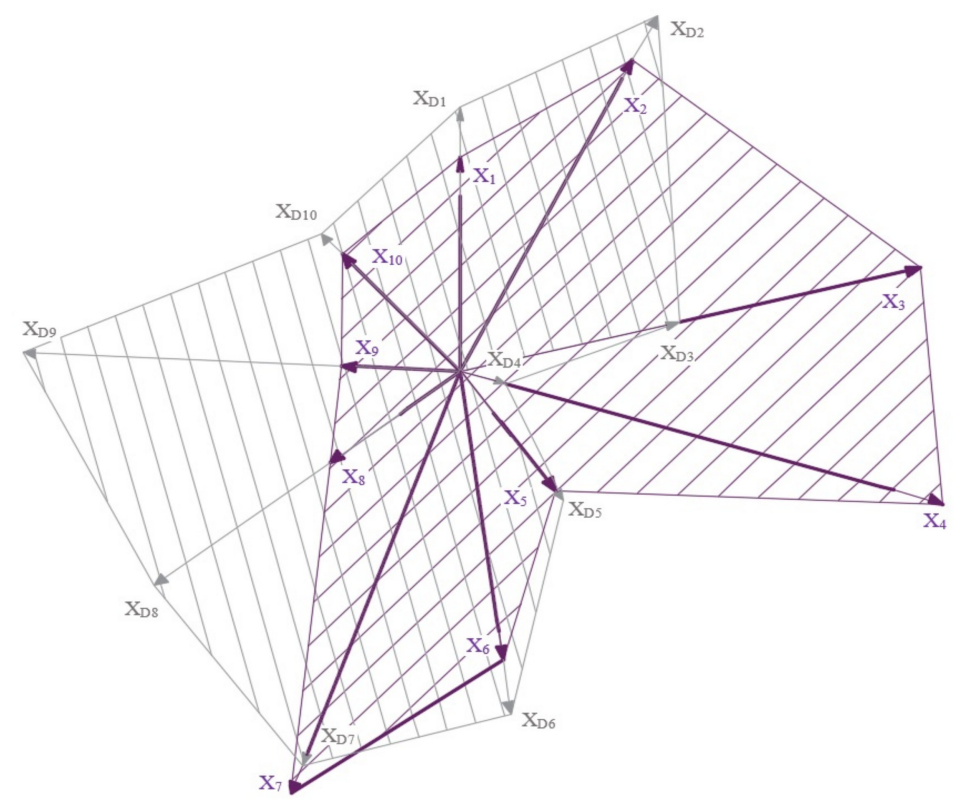

Figure 4. Graphic interpretation of the vector components for mixture V.

Based on the obtained test results, the shapes of random variables Zx were determined for particular mixtures.

- $\quad$ for mixture I

$$
\begin{gathered}
Z_{x}=1.0218+2.9138+0.1006+2.2601+0.0012+0.0139+0.0038+0.0147+0.0004+0.0003 \\
Z_{x}=6.3306
\end{gathered}
$$

- $\quad$ for mixture II 
$Z_{x}=0.8389+2.7469+0.1006+2.0277+0.0005+0.0113+0.0038+0.0070+0.0008+0.0002$

$$
Z_{x}=5.7377
$$

- $\quad$ for mixture III

$Z_{x}=0.6828+1.8569+0.0415+2.1449+0.0008+0.0151+0.0026+0.0157+0.0010+0.0001$

$$
\mathrm{Z}_{\mathrm{x}}=4.7614
$$

- $\quad$ for mixture IV

$$
Z_{x}=1.1322+3.7144+0.0469+1.8758+0.0013+0.0168+0.0015+0.0525+0.0011+0.0009
$$

$$
Z_{x}=6.8461
$$

- for mixture V

$$
\begin{gathered}
Z_{x}=1.2588+3.3309+0.0479+0.2111+0.0013+0.0148+0.0035+0.0353+0.0014+0.0004 \\
Z_{x}=4.9054
\end{gathered}
$$

Figure 5 shows standardized results for random variable $Z_{x}$ in the form of diagrams for each mixture.

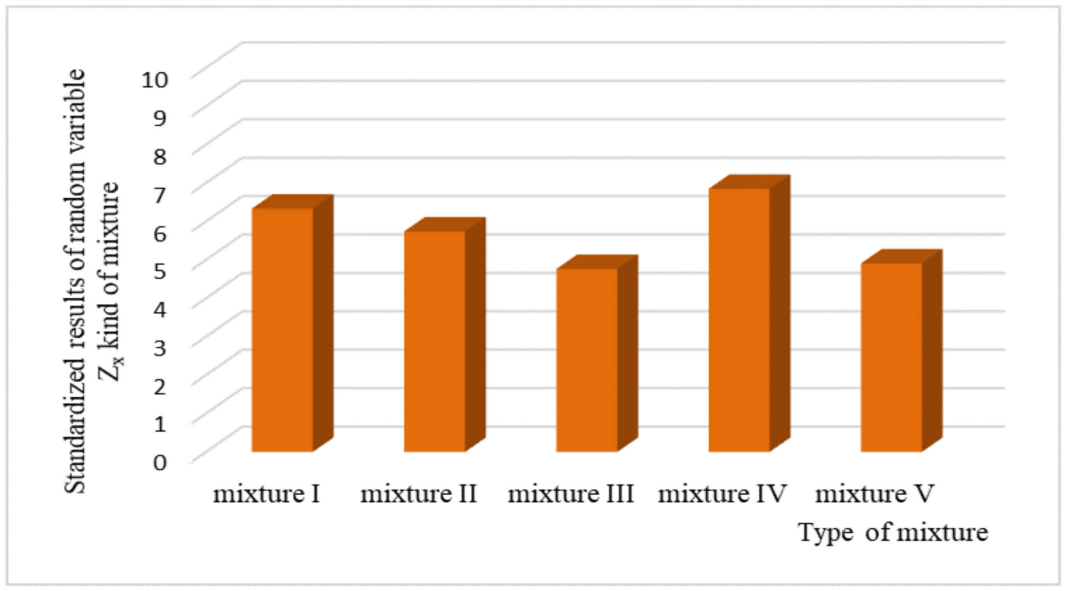

Figure 5. Graphic interpretation of the value of random variable $Z_{x}$.

The values of random variable $Z_{x}$ for particular fuel mixtures $(\mathrm{ON}, \mathrm{BIO} 10, \mathrm{BIO} 0$, $\mathrm{BIO} 50 \mathrm{i} \mathrm{BIO} 50+$ ) represent a sum of the vector components and assigned weights to them. The reference point was mixture ON ('pure' diesel). As the diagram shows, the determined value of the random variable for mixtures II, III and V was lower than the reference point. Whereas, the value reached for the random variable for mixture BIO50 was higher by almost $8 \%$ than that of the 'pure' diesel. Therefore, based on the analysis, and using the accepted assessment parameters, the application of mixture IV-BIO50 was found to be advisable, as it was characterized by the most beneficial performance properties for both the engine operation and the environment. 


\subsection{Statistical Analysis of the Results}

The experiment results underwent statistical analysis to provide information on the studied relationships. For this purpose, a comparison of the mixture mean values was carried out.

Five mixtures of diesel fuel and fatty acid methyl esters were compared. Each of the presented mixtures (I, II, III, IV, V) was tested five times. In these tests, 10 performance parameters of the drive unit were measured. The hypothesis of means/medians equality was accepted. Significance levels are presented in Table 9 for the mean value comparative test.

Table 9. Verification of the hypothesis for the analyzed parameters [6]

\begin{tabular}{lccccc}
\hline Parameters & I & II & III & IV & V \\
\hline Power [kW] & 0.0001 & 0.0001 & 0.0001 & 0.0001 & 0.0001 \\
\hline Torque [Nm] & 0.0001 & 0.0001 & 0.0001 & 0.0001 & 0.0001 \\
\hline Emission of sound generated by the engine [dB] & 0.0001 & 0.0001 & 0.0006 & 0.0001 & 0.5171 \\
\hline Content of particulates in exhaust gases [ppm] & 0.0001 & 0.0001 & 0.0001 & 0.0001 & 0.0001 \\
\hline Carbon monoxide [\% vol.] & 0.1331 & 0.0001 & 0.1015 & 0.0039 & 0.0003 \\
\hline Carbon dioxide [\% vol.] & 0.0415 & 0.3460 & 0.0802 & 0.0381 & 0.0302 \\
\hline Oxygen [\% obj.] & 0.0001 & 0.0001 & 0.0001 & 0.7957 & 0.0002 \\
\hline Nitric oxides [ppm] & 0.1172 & 0.3548 & 0.3714 & 0.0009 & 0.0001 \\
\hline Air excess coefficient lambda & 0.0427 & 0.8826 & 0.0006 & 0.0009 & 0.0001 \\
\hline Hydrocarbons [ppm] & 0.0001 & 0.0001 & 0.0001 & 0.0001 & 0.0001 \\
\hline
\end{tabular}

The table includes the results of the significance level, where $p=0.0001$ means that the actual significance level was smaller. In eight cases, the value exceeded the established significance level. For these cases, there were no grounds to reject the equality of the means/medians hypothesis.

In the next stage, the relationships between the performance parameters were analyzed, depending on the mixture content. The analyzed population was a 150-element sample $\mathrm{n}$, which, for the studied parameters $\mathrm{x}$ and $\mathrm{y}$, provided definite measurement results. The amount of fatty acid methyl ester additives to the diesel fuel was determined as $X$, and $y$ was used to determine the results of the performance parameter tests on individual values for individual mixtures. Hence, in the regression analysis, the percentage of fatty acid methyl esters in the diesel fuel was an independent variable, and the dependent variables were the individual values of the engine performance parameters. In the case of engines powered with plant oil fuels, the interpretation of regression function in the statistical model is about the applicability of the variables for the prediction of the level of the dependent variables.

This work presents exemplary regression function equations for the performance parameters of a transport-means power unit. Below, there is an exemplary analysis of a test of the solid particle content in exhaust gases for mixture IV. A regression straight was obtained by marking the empirically provided points on the diagram. A diagram of the studied linear regression is presented in Figure 6. 


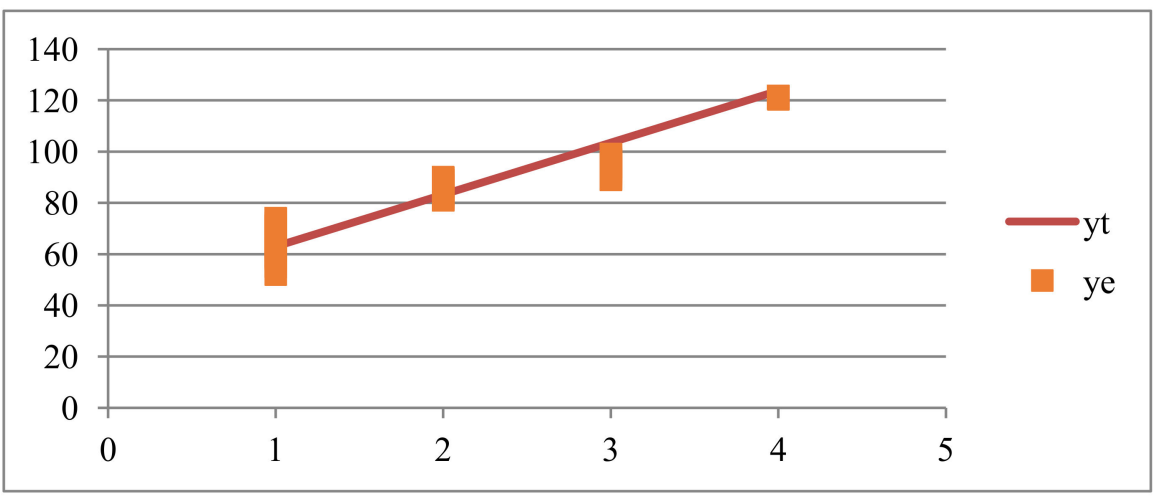

Figure 6. Diagram of linear regression of the particulate parameter for mixture IV.

The above diagram shows the empirical points marked as ye, along with a regression straight yt, determined for theoretical parameters.

The least squares method was used to determine the values of the estimators a and b. The differences between the measurement values and their mean value, as well as the values of the defined functions, were also calculated. On this basis, a simple regression was determined in the form:

$$
y=20.265 x+42.722
$$

For the above regression equation, the correlation coefficient was $r=0.974$. Tests of hypothesis H0: $\mathrm{a}=0$ yielded $p<0.0001$, which means that the studied dependence is statistically significant.

Analogically, an analysis was performed for each parameter of the respective mixtures.

\section{Discussion}

The whole discussion included in this study is supposed to show the impact of a biofuel component additive to diesel fuel as an alternative fuel from the perspective of sustainable development policy, particularly in the automotive industry. These solutions need to be consistent with already existing technologies (in the analyzed case, power and torque of a power unit), and take into account the implementation costs, including the prices of fuel and its consumption. On the other hand, the actions to be taken should also take into account a widely understood interest of future generations, including the exhaustion of natural resources, an assessment of the impact of given solutions on the life of people and animals, and environmental protection. When making a comparative analysis of the toxic parameter values of exhaust gases emitted by transport means powered with the so-called 'pure' diesel and a fuel with biocomponent additives, a question arises as to whether this policy is justified in terms of all the above mentioned aspects.

Emissivity reduction in a self-ignition engine while maintaining its high efficiency needs to be further explored for ecological reasons. The conducted tests have confirmed that the use of fuels from renewable sources contributes to reduction in the emissions of exhaust gases harmful to the natural environment, which has been proven by many authors involved in this subject [11,39-49]. The tests described in this study were performed for the standard settings of the vehicle deck computer. The literature does not provide information on the adjustment of the fuel injection controller, which would allow the matching of a given setting with the optimal operation of the drive unit of a given transport means powered with a mixture of diesel oil and fatty acid methyl esters. The adjustment of the vehicle deck computer would allow efficient operation of the engine (maintaining its power and torque) with the reduction in the harmful content of exhaust gases. In the next stage of the experiment, the performance of measurements of the engine fuel injection controller adjustments is planned. 


\section{Summary and Conclusions}

The presented methodology and the proposed model enable assessment and inference regarding the applicability of a given fuel, depending on the accepted (optional) assessment parameters.

Based on the experimental tests, the following conclusions have been formulated:

- $\quad 30 \%$ and more of a fatty acid methyl ester additive to diesel fuel is a threshold value for its applicability, due to the power and torque criterion;

- The analysis of the values of the operating parameters of the drive unit of the means of transport, carried out on the basis of a random variable defined for this object, showed that the best results were obtained for mixture IV, and the worst for mixture III;

- The assessment shows that it was the criteria of power and torque that were most affected by the fuel mixture content, whereas the emission of carbon dioxide and nitric oxides were the least affected;

- The application of fatty acid methyl esters in diesel fuel had a positive impact on a reduction in the emission of noise generated by the transport-means power unit;

- The assessment shows that the composition of the fuel blend had the greatest impact on the criterion of power and torque of the drive unit of the measured transport, and the lowest emissions of carbon dioxide and nitrogen oxides;

- The performed statistical analysis makes it possible to define guidelines to be developed into decision-making strategies regarding the correct composition of the fuel mixture;

- Changes in the properties of the tested operational parameters of the drive unit of the means of transport are presented in a vector manner, which allows for a simultaneous analysis of changes in the tested parameters;

- The analysis makes it possible to set the guidelines for the development of a decisionmaking strategy for the application of appropriate content of the fuel mixture to be used in a car.

Author Contributions: Conceptualization: Ł.M., M.P. and M.M.; formal analysis: M.M.; investigation: M.M.; methodology: Ł.M., M.M. and D.K.; resources: M.M.; visualization: M.M. and T.K.; writing —original draft: M.M.; writing—review and editing: M.M. All authors have read and agreed to the published version of the manuscript.

Funding: The research did not receive external financing.

Institutional Review Board Statement: Not applicable.

Informed Consent Statement: Not applicable.

Data Availability Statement: Not applicable.

Conflicts of Interest: The authors declare no conflict of interest.

\section{References}

1. Struś, M. Efficiency of self ignition combustion engines powerd with bioxdiesel with fuly renewable components. Mach. Eng. 2014, 14, 29-38.

2. Dzieniszewski, G. Selected problems of biofuels for powering delf ignition engines. Agric. Eng. 2008, 10, 39-45.

3. Arapaki, N.; Bekeas, E.; Karavalakis, G.; Tzirakis, E.; Stournas, S.; Zannikos, F. Regulated and unregulated emission characteristics of diesel vehicle operating with diesel biodiesel blend. SAE Tech. Pap. 2007, 1, 1-9.

4. Bala, B.K. Studies on biodiesels from transformation of vegetable oils for diesel engines. Energy Educ. Sci. Technol. $2005,15,1-43$.

5. Karavalakis, G.; Kousoulidou, M.; Tzamkiozis, T.; Ntziachristos, L.; Bakeas, E.; Stournas, S.; Samaras, Z. Effects of biodiesel on passenger car fuel consumption, regulated and non-regulated pollutant emissions over legislated and real-world driving cycles. Fuel 2009, 88, 1608-1617.

6. Knothe, G.; Sharp, C.; Ryan, T. Exhaust emission of biodiesel, petrodiesel, neat methyl esters and alkanes in a new technology engine. Energy Fuels 2006, 20, 403-408. [CrossRef]

7. Ozer, C.; Ozturka, E.; Solmazb, H.; Aksoyc, F.; Çinarb, C.; Yucesub, S. Combined effects of soybean biodiesel fuel addition and EGR application on the combustion and exhaust emissions in a diesel engine. Appl. Therm. Eng. 2016, 95, 115-124. 
8. Azoumaha, Y.; Blinac, J.; Dahob, T. Exergy efficiency applied for the performance optimization of a direct injection compression ignition engine using biofuels. Renew. Energy 2009, 34, 1494-1500. [CrossRef]

9. Tompkins, B.; Song, H.; Bittle, J.; Jacobs, T. Efficiency considerations for the use of blended biofuel in diesel engines. Appl. Energy 2012, 98, 209-218. [CrossRef]

10. Man, X.; Cheung, C.; Ning, Z.; Wei, L.; Huang, Z. Influence of engine load and speed on regulated and unregulated emissions of a diesel engine fueled with diesel fuel blended with waste cooking oil biodiesel. Fuel 2016, 180, 41-49. [CrossRef]

11. Armas, O.; Yehliu, K.; Boehman, A. Effect of alternative fuels on exhaust emission during diesel engine operation with matched combustion phasing. Fuel 2010, 89, 438-456. [CrossRef]

12. Chauhan, B.; Kumara, N.; Chob, H.; Limc, H. A study on the performance and emission of a diesel engine fueled with Karanja biodiesel and its blends. Energy 2013, 56, 1-7. [CrossRef]

13. Hoekman, S.; Robbins, C. Review of the effects of biodiesel on NOx emissions. Fuel Process. Technol. 2012, 96, 237-249. [CrossRef]

14. Necati, A.; Canakci, O. Determination of performance and combustion characteristics of a diesel engine fueled with canola and waste palm oil methyl esters. Energy Convers. Manag. 2011, 52, 108-116.

15. Ozener, O.; Yuksek, L.; Ergenç, T.; Ozkan, M. Effects of soybean biodiesel on a DI diesel engine performance, emission and combustion characteristics. Fuel 2014, 115, 875-883. [CrossRef]

16. Xue, J.; Grift, T.; Hansen, C. Effect of biodiesel on engine performances and emissions. Renew. Sustain. Energy Rev. 2011, 15, 1098-1116. [CrossRef]

17. Rakopoulos, C.; Dimaratos, A.; Giakoumis, E.; Rakopoulos, D. Study of turbocharged diesel engine operation, pollutant emissions and combustion noise radiation during starting with bio-diesel or n-butanol diesel fuel blends. Appl. Energy 2010, 88, 3905-3916. [CrossRef]

18. Belgiorno, G.; Boscolo, A.; Dileo, G.; Numidi, F.; Concetto Pesce, F.; Vassallo, A.; Ianniello, R.; Beatrice, C.; Di Blasio, G. Experimental Study of Additive-Manufacturing-Enabled Innovative Diesel Combustion Bowl Features for Achieving Ultra-Low Emissions and High Efficiency. SAE Int. J. Adv. Curr. Pract. Mobil. 2020, 130, 672-684. [CrossRef]

19. Guido, C.; Beatrice, C.; Di Iorio, S.; Napolitano, P.; Di Blasio, G.; Vassallo, A.; Ciaravino, C. Assessment of Closed-Loop Combustion Control Capability for Biodiesel Blending Detection and Combustion Impact Mitigation for an Euro5 Automotive Diesel Engine; SAE 2011 World Congress \& Exhibition; SAE International: Pittsburgh, PA, USA, 2011.

20. Sivaramakrishnan, K.; Ravikumar, P. Determination of cetane number of biodiesel and it's influence on physical properties. ARPN J. Eng. Appl. Sci. 2012, 7, 2.

21. Woropay, M.; Muślewski, Ł. Quality as a system on example of transport system. J. KONES Intern. Combust. Engines 2004, 11, 334-346.

22. Woropay, M.; Muślewski, Ł.; Piętak, A.; Niezgoda, T.; Żurek, J. The application example of the evaluation model in the case of the transport system operation quality. ACSIM 2004, 2, 220-226.

23. Pajak, M.; Muślewski, Ł. Fuzzy model of quality assessment of operation of a complex operation system. In Proceedings of the 10th Jubilee Congress of Technical Equipment Operation, ITE, Warsaw, Poland, 11-12 December 2005.

24. Sharma, D. Designing and Modeling Fuzzy Control Systems. Int. J. Comput. Appl. 2011, 16, 46-53. [CrossRef]

25. Broniewicz, E.; Ogrodnik, K. Multi-criteria analysis of transport infrastructure projects. Transp. Res. Part D: Transp. Environ. 2020, 83, 102351. [CrossRef]

26. Camargo Perez, J.; Carrillo, M.; Montoya-Torres, J. Multi-criteria approaches for urban passenger transport systems: A literature review. Ann. Oper. Res. 2015, 226, 69-87. [CrossRef]

27. Sawik, B.; Faulin, J.; Pérez-Bernabeu, E. Multi-Criteria Optimization for Fleet Size with Environmental Aspects. Transp. Res. Procedia 2017, 27, 61-68. [CrossRef]

28. De Luca, S. Public engagement in strategic transportation planning: An analytic hierarchy process based approach. Transp. Policy 2014, 33, 110-124. [CrossRef]

29. Duleba, S.; Moslem, S. Examining Pareto optimality in analytic hierarchy process on real Data: An application in public transport service development. Expert Syst. Appl. 2019, 116, 21-30. [CrossRef]

30. Demirbas, A. Importance of biodiesel as transportation fuel. Energy Policy 2007, 35, 4661-4670. [CrossRef]

31. Ali, O.; Mamat, R.; Abdullah, N.; Abdullah, A. Analysis of blended fuel properties and engine performance with palm biodieseldiesel blended fuel. Renew. Energy 2016, 86, 59-67. [CrossRef]

32. Alptekin, E. Emission, injection and combustion characteristics of biodiesel and oxygenated fuel blends in a common rail diesel engine. Energy 2017, 119, 44-52. [CrossRef]

33. Wang, L.; Wang, J.; Xiao, J. Combustion and emission characteristics of diesel engine fueled with diesel/biodiesel/pentanol fuel blends. Fuel 2015, 156, 211-218.

34. E-Petrol. Available online: https:/ / www.e-petrol.pl/quotes/biofuels (accessed on 10 January 2021).

35. Markiewicz, M.; Muślewski, Ł. Survey performance and emission parameters of diesel engine powered by diesel oil and fatty acid methyl esters using fuzzy logic techniques. Fuel 2020, 277, 118179. [CrossRef]

36. Markiewicz, M.; Muślewski, Ł.; Pajakk, M. Impact of Biocomponent Additive to Diesel Oil on Values of Selected Functional Parameters of Transport Means. Pol. J. Environ. Stud. 2020, 29, 3475-3483. [CrossRef]

37. Velasquez, M.; Hester, P. An Analysis of Multi-Criteria Decision Making Methods. Int. J. Oper. Res. $2013,10,2$. 
38. Agarwal, A.K.; Srivastava, D.K.; Dhar, A.; Maurya, R.K.; Shukla, P.C.H.; Singh, A.P. Effect of fuel injection timing and pressure on combustion, emissions and performance characteristics of a single cylinder diesel engine. Fuel 2013, 111, 374-383. [CrossRef]

39. Choi, S.; Oh, Y. The emission effects with the use of biodiesel fuel. Int. J. Mod. Phys. B 2006, 20, 4481-4486. [CrossRef]

40. Lapuerta, M.; Armas, O.; Rodriguez-Fernandez, L. Effect of biodiesel fuels on diesel engine emission. Prog. Energy Combstion Sci. 2008, 34, 198-223. [CrossRef]

41. Leung, D.; Luo, Y.; Chan, T. Optimization of exhaust emission of a diesel engine fuelled with biodiesel. Energy Fuels 2006, 20, 198-223. [CrossRef]

42. Muślewski, Ł.; Pajak, M.; Landowski, B.; Żółtowski, B. A method for determining the usability potential of ship steam boilers. Pol. Marit. Res. 2016, 23, 105-111. [CrossRef]

43. Jablonicky, J.; Tkac, Z.; Majdan, R.; Mullerova, D.; Hujo, L.; Vozarova, V. Hodnotenie Vlastnosti Biopaliw a Biomazin; Slovak University of Agriculture in Nitra, Fakulty of Engineering: Nitra-Chrenová, Slovakia, 2012; ISBN 978-80-552-0766-7.

44. Curkowski, A.; Mroczkowski, P.; Oniszk-Ppławska, A.; Wiśnieski, G. Agricultural Biogas Production and Utilization; Mazowiecka Energy Agency: Warszawa, Poland, 2009.

45. Markiewicz-Patalon, M.; Muślewski, Ł.; Kaszkowiak, J.; Sójka, M. Analysis of Efficiency of the Vehicle Transport Facilities Powered with Diesel Oil with Additive of Biocomponent; KONMOT: Kraków, Poland, 2018; pp. 297-299.

46. Markiewicz-Patalon, M.; Muślewski, Ł.; Kaszkowiak, J. Noise Emission Research of Diesel Engine Powered with Mixture of Diesel Oil and Methyl Esters; KONMOT: Kraków, Poland, 2018; pp. 272-274.

47. Muślewski, $€$. The implementation of the fuzzy logic elements in the area of the transport system operation quality assessment. Maritime Industry, Ocean Engineering and Coastal Resources. Maritime Transportation. In Balkema-Proceedings and Monographs in Engineering, Water and Earth Sciences; Soares, C.G., Kolev, P.N., Eds.; Taylor \& Francis Group: London, UK; Leiden, The Netherlands; New York, NY, USA; Philadelphia, PA, USA; Singapore, 2007; Volume 1.

48. Landowski, B.; Muślewski, $€$. Decision model of an operation and maintenance process of city buses. In Proceedings of the 58th International Conference of Machine Design Departments-ICMD 2017, Praque, Czech Republic, 6-8 September 2017; Czech University of Life Sciences Prague: Praha-Suchdol, Czech Republic, 2017; pp. 188-193.

49. Aleksandrowicz, P. Verifying a truck collision applying the SDC method. In Proceedings of the 58th International Conference of Machine Design Departments, Praque, Czech Republic, 6-8 September 2017; pp. 14-19. 